\title{
Characterization of Dyslipidemia and Assessment of Atherogenic Risk amongst Cameroonian Living in Yaounde: A Cross Sectional Study
}

\author{
Huguette Cecile Mafo Yangoua ${ }^{1,2}$, Boris Gabin Kingue Azantsa1*, Dieudonne Kuate ${ }^{1,3}$, \\ Françoise Raissa Ntentie ${ }^{1,4}$, Maxwell Wandji Nguedjo',2, Jacob Tchinda Nkougni1, \\ Boris Ronald Tonou Tchuente ${ }^{1,2}$, Judith Laure Ngondi' ${ }^{1}$ Julius Oben ${ }^{1}$
}

\author{
${ }^{1}$ Laboratory of Nutrition and Nutritional Biochemistry, Department of Biochemistry, Faculty of Science, University of Yaounde 1, \\ Yaounde, Cameroon \\ ${ }^{2}$ Centre for Food and Nutrition Research, IMPM, Ministry of Scientific Research and Innovation, Yaounde, Cameroon \\ ${ }^{3}$ Department of Biochemistry, Faculty of Science, University of Dschang, Dschang, Cameroon \\ ${ }^{4}$ Higher Teaching' Training College, University of Maroua, Maroua, Cameroon \\ Email: *borisazantsa@yahoo.fr
}

How to cite this paper: Yangoua, H.C.M., Azantsa, B.G.K., Kuate, D., Ntentie, F.R., Nguedjo, M.W., Nkougni, J.T., Tchuente, B.R.T., Ngondi, J.L. and Oben, J. (2019) Characterization of Dyslipidemia and Assessment of Atherogenic Risk amongst Cameroonian Living in Yaounde: A Cross Sectional Study. Journal of Biosciences and Medicines, 7, 35-50.

https://doi.org/10.4236/jbm.2019.77004

Received: June 6, 2019

Accepted: July 8, 2019

Published: July 11, 2019

Copyright $\odot 2019$ by author(s) and Scientific Research Publishing Inc. This work is licensed under the Creative Commons Attribution International License (CC BY 4.0).

http://creativecommons.org/licenses/by/4.0/ (c) (i) Open Access

\begin{abstract}
Background: This study was conducted to evaluate the lipid profile in nutritional categories, to characterize dyslipidemia and assess cardiovascular risk, to describe association between anthropometric markers, incidence of dyslipidemia and cardiovascular risk in Cameroonian adults. Methods: A cross-sectional survey was conducted in Yaoundé from April 2014-June 2015. It included 1986 individuals, aged 20 - 65 years, both males (30.7\%) and females (69.3\%). Blood pressure, anthropometric measurement including weight, height, body fat, waist and hip circumference were performed. BMI was used to define nutritional status. Blood analysis included total cholesterol, HDL-cholesterol and triglycerides, insulin. Dyslipidemia was defined as hypercholesterolemia, hypertriglyceridemia, low HDL-cholesterolemia and combined dyslipidemia. Atherogenic indexes were calculated for assessment of the cardiovascular risk. Results: Out of the 1986 participants, 544 (27.4\%), 616 (31\%), and 826 (41.6\%) were normal weight, overweight and obese respectively. In obese, lipid profile varied according to gender $(\mathrm{p}<0.05)$. In addition, total cholesterol $(\mathrm{p}<0.05)$, LDL-c $(\mathrm{p}<0.05)$ level, total cholester$\mathrm{ol} / \mathrm{HDL}$-cholesterol and LDL-c/HDL-c were higher among obese than normal weight individuals. Hypercholesterolemia (19.3\%), hypertriglyceridemia (11.64\%), combined dyslipidemia (3.40\%) and the atherogenic profile (Total cholesterol/HDL-cholesterol ratio > 5) was (40.50\%). Low HDL-cholesterolemia (75.4\%)
\end{abstract}


was the main lipid abnormality found, independently of gender, age, fat location. Waist circumference (WC) unlike body mass index (BMI) and body fatness was associated to hypercholesterolemia. Conclusion: Low HDL-cholesterolemia and high atherogenic risk profile are more prevalent amongst Cameroonian adults. Promotion of healthy lifestyle including good eating habits shall be encouraged to reduce mortality from cardiovascular disease complications.

\section{Keywords}

Dyslipidemia, Obesity, Atherognic Risk, Lipid Markers, Cameroon

\section{Introduction}

Evidence of sudden and unexpected death is common in Cameroon amongst apparently healthy people, probably due to cardiovascular diseases (CVD) [1] [2]. CVD have been reported to be responsible for at least two-thirds of cardiovascular deaths in sub-Saharan Africa, with hypertension, smoking and obesity being the leading team [2]. The prevalence of obesity and metabolic disorders is increasing across Africa [3] [4] [5] and in Cameroon [6] [7]. Obesity in Cameroon affects children [8] and adults [9] [10] in both urban and rural areas [6]. Defined as a condition with excessive fat accumulation that adversely affected health and well-being [11] [12], obesity constitutes global public health problem due to its association with several diseases [13], and reduced lifespan [14] [15]. Obesity results from complex interaction of genetic, lifestyle, dietary habits, energy expenditure, nutritional and metabolic factors as the adipocyte metabolism [15] [16]. Fat accumulation and location constitute risk factors for diabetes, cardiovascular diseases [2] and dyslipidemia [17]. Dyslipidemia is a condition of an abnormal lipid or lipoprotein concentration in the blood. Dyslipidemia includes elevated cholesterol, high triglycerides and lower high-density lipoprotein (HDL-c) cholesterol levels which have been reported to increase cardiovascular risk [18] [19]. Evidence reports that dyslipidemia profile differs according to race or ethnicity of the populations. In fact, ethnicity determines different adipose tissues distribution and responses to the cardio-metabolic risks [20]. For instance, the Framingham and Examination Surveys (NHANES) from 2003-2006 study [21] have shown hypercholesterolemia and high LDL-Cholesterolemia as key features of dyslipidemia that cause lesions in the US population. Low HDL cholesterolemia as main dyslipidemia was reported in China [17] and in Nigeria [5]. Evidence further proved that even in the same population, lipid profile differs in subgroup of obese individuals, with different metabolic and cardiovascular risk profiles [22]. Therefore, the attempt to manage dyslipidemia and reduce cardio-metabolic risk of a patient requires better understanding of the population specificities for better and adequate treatment approaches. Cameroon like many other low-income countries is un- 
dergoing social, economic and dietary changes, resulting from increased urbanization with a potentially negative impact on health-related behaviors [2] [6] [19]. Given that only few data document dyslipidemia profile and their incidence on cardiovascular risk of Cameroonian, this study was carried out to describe lipid profile across BMI categories, to identify the most common dyslipidemia, to examine the association between anthropometric markers, dyslipidemia and cardiovascular risk in apparently healthy adults living in Yaoundé.

\section{Materials and Methods}

\subsection{Study Design and Setting Population}

A cross-sectional survey was carried out from April 2014 to June 2015 on 2500 eligible individuals living in Yaounde, the city capital of Cameroon. Participants were informed through radio announcement, flyers and posters displayed around town. They were invited to attend nutrition education programs organized by the Cameroon Nutrition Science Society hosted by Laboratory of Nutrition and Nutritional Biochemistry (LNNB), University of Yaounde 1. The study follows the workflow chart in Figure 1.

\subsection{Inclusion and Exclusion Criteria}

Inclusion criteria for study participation were: 1) Individuals aged 20 to 65 years, diagnosed by a physician as being physically healthy (absence of hospitalization); 2) stable body weight $( \pm 2 \mathrm{~kg})$ for at least three months, without use of medication known or suspected to affect body weight or appetite; 3) BMI above 18.5 $\mathrm{kg} / \mathrm{m}^{2}$; 4) no weight loss attempts through dietary intervention over the three months; 5) non-diabetic; 6) nonsmoker; and 7) ability to competently understand

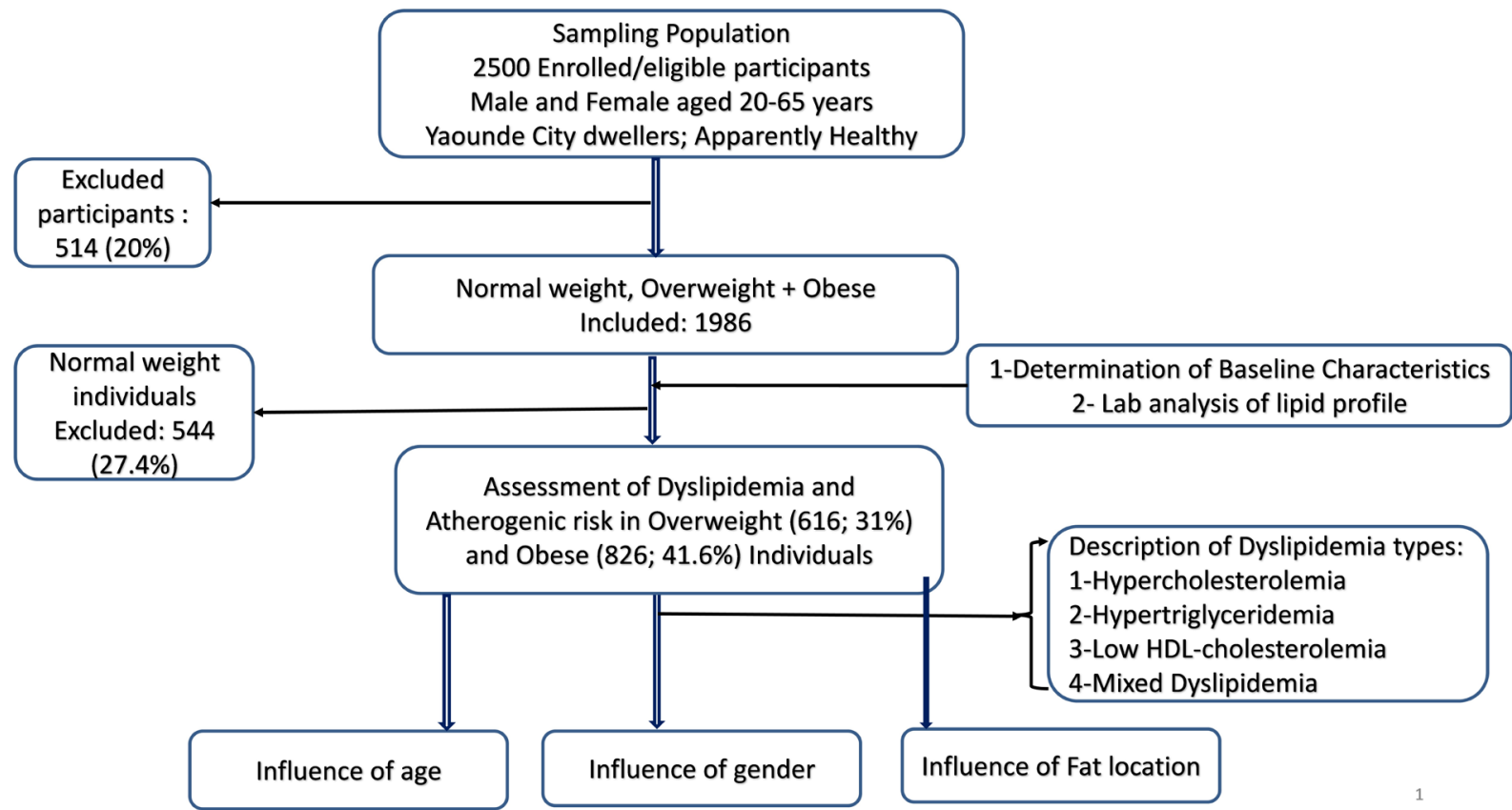

Figure 1. Work flowchart of the study. 
and sign the consent form. Excluded were pregnant or breast-feeding women, individuals with known endocrine disorder particularly hypothyroidism, liver and kidney diseases. Based on the above criteria, 20.56\% (514) were excluded and 1986 (609 men and 1377 women) consenting volunteers were selected to participate in the study (Figure 1). Questionnaires were administered, anthropometric measurements performed, and blood sample collected from patients.

\subsection{Ethics Approval and Consent to Participate}

The study was conducted according to protocol No. 2014/08/488/CE/CNERSH/, approved by the Cameroon National Ethics Committee for Research on Human Health. All participants were treated according to the Helsinki declaration. They provided written and signed a consent form.

\subsection{Study Questionnaire}

A structured questionnaire conceived from WHO STEPwise Instrument for chronic diseases v2.1. was used to collect socio-demographic data, family history, clinical symptoms, and medical treatment for various chronic diseases, smoking and alcohol consumption. LNNB Researchers were trained to administer questionnaires, through a face-to-face interview with participants.

\subsection{Anthropometric Measurements}

Height was measured with a wall mounted stadiometer, which was calibrated against the Cameroon's Department of National Security identification scale. Body weight and body fatness (BF), were assessed using a Tanita ${ }^{\text {Tx }}$ BC-418 Segmental Body Composition Analyzer/Scale based on bioelectrical impedance principle. Waist circumference (WC) was measured at the mid-point between the highest part of the iliac crest and the lowest part of the ribs margin of the median axial line. Body mass index (BMI) was calculated by dividing the weight in kilograms by the height in $\mathrm{m}^{2}$. Blood Pressure was measured as well. Briefly, the participants left arm was placed at the level of the heart in a sitting position and blood pressure was measured with a digital two of three readings sphygmomanometer (Omron 770A, Omron Corporation, Kyoto, Japan). The averages of the two last three systolic and diastolic pressures were recorded and the first reading was excluded.

\subsection{Laboratory Data and Analysis}

After a 12-hour overnight fast, venous blood was collected in EDTA test tubes, then centrifuged at $4500 \mathrm{G}$ for $10 \mathrm{~min}$, plasma obtained was stored in aliquots. Reagents from the same batch were used to minimize laboratory variability [23]. Samples were analyzed to determine total cholesterol, high-density cholesterol (HDL-c) and triglycerides using Chronolab test kits with semi-automated spectrophotometer in accordance with the international quality standard. Fasting blood glucose (FBG) was measured based on glucose-oxidase method using a 
glucometer and test strips (One-touch plus). Fasting plasma insulin was determined with ELISA method and microplate reader spectrophotometer. Plasma LDL cholesterol was calculated using Friedewald's equation, except when triglycerides exceeded $400 \mathrm{mg} / \mathrm{dL}$ [24].

\subsection{Definitions}

Dyslipidemia: The classification of the reference values for total cholesterol, triglycerides, LDL-C, and HDL-C followed the criteria of the Adult Treatment Panel III of the National Cholesterol Education Program (NCEP-ATPIII) [25] on dyslipidemia, Hypertriglyceridemia was defined as plasma concentration triglycerides $\geq 150 \mathrm{mg} / \mathrm{dL}$ or $1.7 \mathrm{mmol} / \mathrm{L}$; hypercholesterolemia was defined as plasma concentration $\geq 200 \mathrm{mg} / \mathrm{dL}$ or $5.17 \mathrm{mmol} / \mathrm{L}$; low HDL-c levels were defined as HDL cholesterol concentration $<40 \mathrm{mg} / \mathrm{dL}$ or $1.03 \mathrm{mmol} / \mathrm{L}$ in men or $<50 \mathrm{mg} / \mathrm{dL}$ or $1.29 \mathrm{mmol} / \mathrm{L}$ in women and mixed/combined dyslipidemia defined (triglycerides $\geq 150 \mathrm{mg} / \mathrm{dL}$ and total cholesterol $\geq 200 \mathrm{mg} / \mathrm{dL}$ ). Atherogenic risks were calculated with three indexes: Atherogenic Index of Plasma (AIP) as Log10 (TG/HDL-c); total cholesterol/HDL-c ratio and LDL-cholesterol/HDL-c ratio [26]. Individuals with Total cholesterol/HDL-c ratio $>5$ or LDL-cholesterol/HDL-c ratio $>4$ were considered at high risk of CVD. Nutritional status was defined based on BMI [27] using World Health Organization cut-off points as: normal weight $\left(18.5-24.9 \mathrm{~kg} / \mathrm{m}^{2}\right)$, overweight $\left(25-29.9 \mathrm{~kg} / \mathrm{m}^{2}\right)$ and obesity $(\geq 30$ $\left.\mathrm{kg} / \mathrm{m}^{2}\right)$. Criteria for fat location and adiposopathy included: waist circumference $\geq 102 \mathrm{~cm}$ in men or $\geq 88 \mathrm{~cm}$ in women defined abdominal obesity and Waist to Hip ratio (WHR) was used to define global or general obesity [25]. Normal-weight individuals were excluded at this stage.

\subsection{Statistical Analysis}

Results were expressed as Mean \pm standard deviation. Frequencies and prevalence were expressed as percentages. Statistical package for social sciences (SPSS) for Windows 20.0 was used for analysis of data. Descriptive analysis included the estimation of mean values and standard deviations for continuous variables. Categorical variables were presented as frequencies and Chi square test was used for comparisons. Continuous variables were compared with Student $t$ test and one way analysis of variance (ANOVA) followed by a Bonferroni test as post-hoc test. The odds ratios (OR) adjusted for sex, age at 95\% confidence intervals (CI) for triglyceridemia, hypercholesterolemia and atherogenic indexes were determined using multivariable logistic regression model. Body fat, BMI, and waist circumference were expressed as independent variables. All tests were two-sided and statistical significance was set at $\mathrm{p}<0.05$.

\section{Results}

\subsection{Study Population}

Out of 2500 eligible participants, 20.56\% (514) were excluded from the study, 
because they didn't meet the inclusion criteria. One thousands nine hundred and eighty six (1986) individuals were included and consented to participate (Figure 1). According to BMI categories defining nutritional status, 544 (27.4\%), 616 $(31 \%)$, and $826(41.6 \%)$ individuals were $(\mathrm{p}=0.04)$ normal-weight, overweight and obese, respectively.

The general characteristics of the study population are summarized in Table 1. Participants were relatively young men $(36.08 \pm 0.59$ years, $\mathrm{n}=609,30.7 \%)$ and women $(36.13 \pm 0.37 \mathrm{yrs}, \mathrm{n}=1377,69.3 \%)$; giving a gender ratio $(\mathrm{M} / \mathrm{F})$ of 0.44 . Women had the highest mean BMI values, body fatness and waist circumference. There was no difference found with diastolic Blood pressure and insulin levels of men compared to women. Also, it was observed that $11.1 \%$ of men consumed alcohol at least once a month compared to $2.4 \%$ women.

\subsection{Lipid Profile and Atherogenic Index in Nutritional Subgroups}

Table 2 shows the mean concentrations of total cholesterol (TC), HDL cholesterol (HDLc), LDL cholesterol (LDL-c) and triglycerides (TG) in defined subgroups: normal-weight, overweight and obesity. It was observed that mean values of triglycerides, total cholesterol and LDL cholesterol were within the reference range set for North Americans. However, compare to normal-weight, obese individuals had significantly higher levels of total cholesterol $(158.20 \mathrm{mg} / \mathrm{dL}$ vs $146.90 \mathrm{mg} / \mathrm{dL} ; \mathrm{p}<0.05)$ and LDL cholesterol $(108.46 \mathrm{mg} / \mathrm{dL}$ vs $92.28 \mathrm{mg} / \mathrm{dL} \mathrm{p}<$ $0.05)$. A different trend was observed with triglyceride and HDL-c levels, which were lower $(\mathrm{P}<0.05)$ among obese than normal-weight individuals. In addition, Total Cholesterol and HDL-Cholesterol were higher in obese women than men $(p<0.05)$. Atherognic index of plasma (AIP) was higher in obese compared to

Table 1. General characteristics of the study population.

\begin{tabular}{cccc}
\hline Parameters & Men & Women & p-values \\
\hline Sample size & $609(30.70 \%)$ & $1377(69.30 \%)$ & 0.001 \\
Age (years) & $36.08 \pm 0.59$ & $36.13 \pm 0.37$ & 0.06 \\
Body Mass Index $\left(\mathrm{kg} / \mathrm{m}^{2}\right)$ & $25.68 \pm 0.18$ & $30.43 \pm 0.19$ & 0.001 \\
Body fatness $(\%)$ & $20.91 \pm 0.35$ & $38.80 \pm 0.26$ & 0.001 \\
Waist circumference (cm) & $83.84 \pm 0.53$ & $91.96 \pm 0.47$ & 0.001 \\
Systolic BP (mmHg) & $125.50 \pm 10.25$ & $129.02 \pm 9.50$ & 0.03 \\
Diastolic BP & $81.78 \pm 14.97$ & $83.21 \pm 15.49$ & 0.06 \\
Heart rate (pulse/min) & $75.97 \pm 12.10$ & $71.18 \pm 12.70$ & 0.23 \\
Hip circumference (cm) & $109.87 \pm 17.12$ & $99.31 \pm 12.52$ & 0.04 \\
Waist to hip ratio (WHR) & $0.83 \pm 0.09$ & $0.86 \pm 0.08$ & 0.05 \\
Glycaemia (mg/dL) & $94.72 \pm 11.70$ & $91.52 \pm 6.35$ & 0.26 \\
Insulin (mIU/L) & $13.26 \pm 1.77$ & $10.16 \pm 2.47$ & 0.17 \\
Alcohol consumption & $68(11.1 \%)$ & $33(2.4 \%)$ & 0.04 \\
\hline
\end{tabular}

Results are expressed as mean \pm standard deviation, BP: Blood pressure, WHR: waist to hip ratio. 
Table 2. Lipid profile and atherogenic index in BMI categories.

\begin{tabular}{|c|c|c|c|}
\hline BMI categories & Population $(n=1986)$ & $\operatorname{Men}(n=609)$ & Women $(n=1377)$ \\
\hline \multicolumn{4}{|c|}{ Triglycerides (mg/dL) } \\
\hline Normal-weight & $97.75 \pm 2.88$ & $98.00 \pm 6.89$ & $96.92 \pm 2.79$ \\
\hline Overweight & $86.42 \pm 2.35^{*}$ & $83.70 \pm 2.23^{\star *}$ & $89.15 \pm 3.59^{*}$ \\
\hline Obese & $91.89 \pm 2.00^{*}$ & $90.50 \pm 2.26^{*}$ & $93.02 \pm 4.71$ \\
\hline \multicolumn{4}{|c|}{ Total Cholesterol (mg/dL) } \\
\hline Normal weight & $146.90 \pm 2.26$ & $143.77 \pm 3.06$ & $150.03 \pm 2.24$ \\
\hline Overweight & $149.69 \pm 2.33$ & $145.90 \pm 8.4$ & $153.49 \pm 4.17^{\star}$ \\
\hline Obese & 158. $20 \pm 2.20^{\star *}$ & $152.30 \pm 5.96^{*}$ & $164.11 \pm 2.06^{* * a}$ \\
\hline \multicolumn{4}{|c|}{ HDL-Cholesterol (mg/dL) } \\
\hline Normal weight & $39.55 \pm 1.02$ & $37.72 \pm 1.22$ & $41.38 \pm 1.02$ \\
\hline Overweight & $37.33 \pm 0.90^{*}$ & $39.28 \pm 1.79$ & $35.38 \pm 0.90^{*}$ \\
\hline Obese & $34.94 \pm 0.89^{*}$ & $32.26 \pm 1.88^{*}$ & $37.62 \pm 0.78^{\star * a}$ \\
\hline \multicolumn{4}{|c|}{ LDL-Cholesterol (mg/dL) } \\
\hline Normal-weight & $92.28 \pm 2.42$ & $90.36 \pm 3.21$ & $94.20 \pm 2.37$ \\
\hline Overweight & $98.24 \pm 2.39$ & $102.11 \pm 4.28^{*}$ & $94.37 \pm 2.51$ \\
\hline Obese & $108.46 \pm 5.28^{*}$ & $104.75 \pm 2.25^{* *}$ & $112.17 \pm 2.08^{\star *}$ \\
\hline \multicolumn{4}{|c|}{ Atherogenic Index of Plasma (AIP) } \\
\hline Normal-weight & $0.39 \pm 0.21$ & $0.42 \pm 0.14$ & $0.37 \pm 0.09$ \\
\hline Overweight & $0.37 \pm 0.12$ & $0.33 \pm 0.10^{\star a}$ & $0.40 \pm 0.26$ \\
\hline Obese & $0.42 \pm 0.15^{*}$ & $0.44 \pm 0.17^{\star}$ & $0.39 \pm 0.12^{\star}$ \\
\hline
\end{tabular}

Values are expressed as Mean $\pm \mathrm{SD} ;{ }^{* *} \mathrm{P}<0.01$ compared to normal weight individuals; ${ }^{*} \mathrm{p}<0.05$ compared to normal-weight individuals; a. $\mathrm{P}<0.05$ in comparison between women and men.

overweight and normal individuals.

\subsection{Determination of the Prevalence of Dyslipidemia and High Atherognic Risk}

The prevalence of hypercholesterolemia, hypertriglyceridemia and mixed hyperlipidemia determined among overweight and obese of the study population were relatively low: $19.30 \%, 11.64 \%$, and $3.40 \%$, respectively. Mixed hyperlipidemia was not associated to the gender (Table 3). Despite low levels of LDL-c, the prevalence of cardiovascular risk was high in the population between $37.50 \%$ to $40.30 \%$ for TC/HDL-c $>5$ and LDLc/HDL-c > 4, respectively. It was also observed a very high prevalence of low HDL cholesterolemia (75.4\%); higher in women than men. The cardiovascular risk was high with both indexes LDL-C/C-HDL > 4 (37.5\%) and TC/ HDL-c > 5 (40.30\%).

\subsection{Dyslipidemia and Fat Location or Adiposopathy}

The prevalence of dyslipidemia profiles according to fat location is shown in Figure 2. It was observed that prevalence of hypertriglyceridemia in abdominal 
Table 3. Prevalence of lipid abnormalities in obese and overweight individuals.

\begin{tabular}{cccc}
\hline Dyslipidemia profiles & $\begin{array}{c}\text { Population }(\mathrm{n} \\
\mathbf{1}\end{array}$ & $\begin{array}{c}\text { Men } \\
(\mathrm{n}=319)\end{array}$ & $\begin{array}{c}\text { Women } \\
(\mathrm{n}=1112)\end{array}$ \\
\hline Hypertriglyceridemia $(\mathrm{TG} \geq 150 \mathrm{mg} / \mathrm{dL})$ & 11.64 & 10.38 & $12.90^{\mathrm{a}}$ \\
$\begin{array}{c}\text { Hypercholesterolemia }(\mathrm{TC} \geq 200 \mathrm{mg} / \mathrm{dL}) \\
\text { Low HDL-cholesterol level (HDL-c }<40 \mathrm{mg} / \mathrm{dL} \\
\text { in men and }<50 \mathrm{mg} / \mathrm{dL} \text { in women) }\end{array}$ & 19.30 & 16.83 & $21.77^{\mathrm{a}}$ \\
$\begin{array}{c}\text { Mixed dyslipidemia }(\mathrm{TC} \geq 200+\mathrm{TG} \geq 150) \\
\text { T C /HDL-c }>5\end{array}$ & 3.40 & 69.76 & $81.04^{\mathrm{a}}$ \\
LDL- c/HDL-c $>4$ & 40.30 & 40.48 & 3.5 \\
\hline
\end{tabular}

a. $\mathrm{P}<0.01$ in comparison between women and men; Results are expressed as percentage (\%).

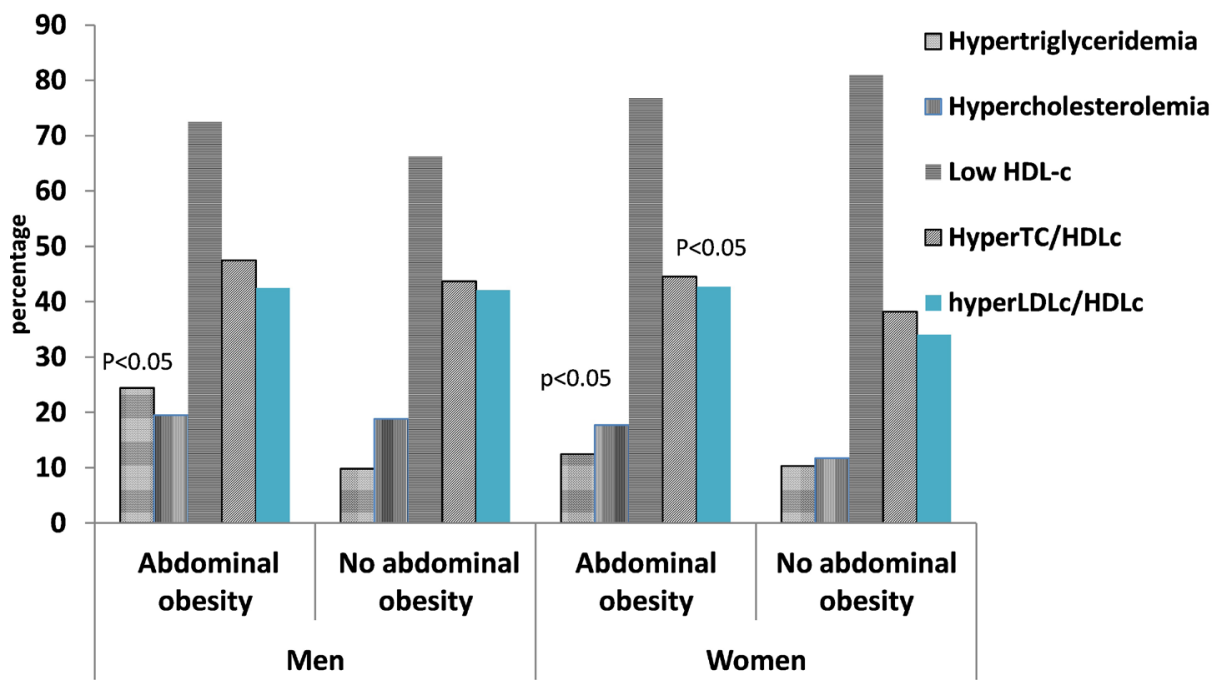

HDL-c: High Density Lipoprotein Cholesterol; Low Density Lipoprotein Cholesterol; CT: Total Cholesterol

Figure 2. Distribution of dyslipidemia according to fat location.

obesity was 2.5 times higher in men $(24.4 \%)$ compared $(\mathrm{p}<0.01)$ to individuals with generalized fat distribution or global obesity (9.80\%). However, there was no difference $(p>0.05)$ in prevalence of triglyceridemia of women with abdominal obesity compared to men with total obesity. Hypercholesterolemia was found in $17.7 \%$ obese women with abdominal obesity, significantly higher compared to $11.7 \%$ found in obese women with total obesity. It has also been observed that independently of fat location and gender, low HDL-cholesterol was predominant in the study population. Prevalence of cardiovascular risk evaluated with two atherogenic indexes revealed an elevated risk $(\mathrm{p}=0.03)$ with visceral accumulation of fat both in men and in women.

\subsection{Variation of Dyslipidemia Profile with Age and Gender}

It appears that independently of fat location, Low HDL-cholesterolemia remains the commonest dyslipidemia in the study population. Its prevalence was higher in men younger than 39 years $(74.2 \%)$ compared $(\mathrm{p}<0.01)$ to those above 39 
(62.2\%), while amongst women, the prevalence is higher as from 20 years (78.5\%). Similar trend was observed with prevalence of cardiovascular risk. Higher atherogenic indexes were observed amongst individuals aged $>50$ years $(P>0.05)$. Furthermore, men aged 30 - 39 years had significantly $(\mathrm{p}<0.05)$ higher frequency of hypertriglyceridemia than men of other age groups, while higher frequency of hypercholesterolemia was observed in men aged 40-49 years, but in women $(\mathrm{p}<0.05)$ older than 50 years (Figure 3$)$.

\subsection{Association between Anthropometric Parameters, Dyslipidemia and Atherogenic Risk}

Following the assessment of the anthropometric parameters involved in the development of lipid abnormalities, univariate regression analyses revealed that increase of one unit of body mass index $\left(1 \mathrm{~kg} / \mathrm{m}^{2}\right)$, increase 1.034 time the risk to develop hypercholesterolemia. However, after age and gender adjustment, it appears in univariate analysis that BMI, WC, BF were strongly associated with hypertriglyceridemia and high atherogenic risk, meanwhile only Body mass index (BMI) and waist circumference (WC); but not body fatness (BF) were associated with hypercholesterolemia. Waist circumference was the main prediction factor in hypercholesterolemia and even remained as the only variable influencing the model in multivariate analyses adjusted for age and gender (Table 4).

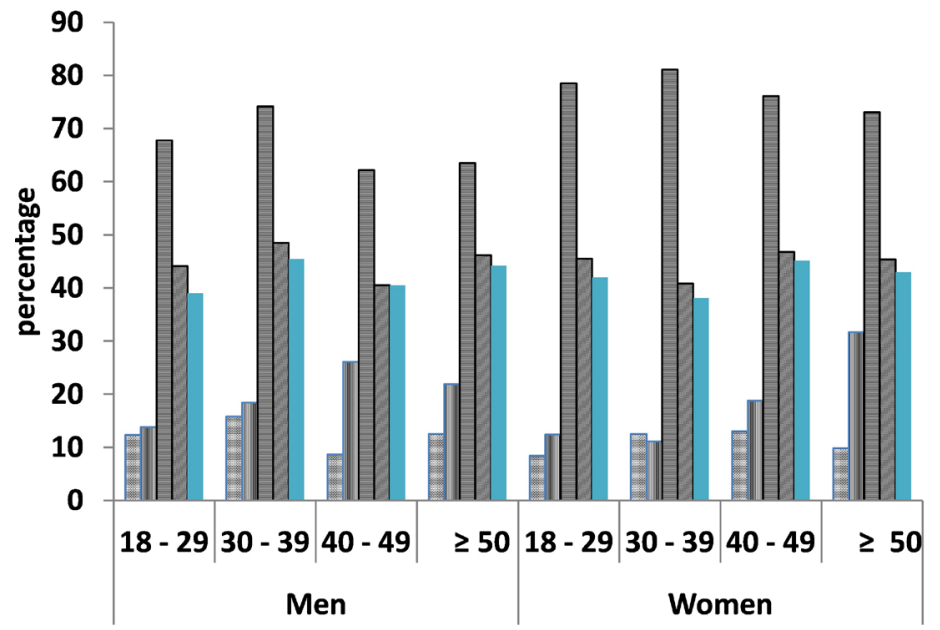

Hypertriglyceridemia

II Hypercholesterolemia

$\square$ Hypohdlemia

$\square$ HyperTC/HDL-c

hyper LDLC/HDLC

HDL-c: High Density Lipoprotein Cholesterol; Low Density Lipoprotein Cholesterol; CT: Total Cholesterol.

Figure 3. Distribution of dyslipidemia according age and gender.

Table 4. Association between markers of obesity and lipid abnormalities.

\begin{tabular}{ccccc}
\hline Variable & $\begin{array}{c}\text { Hypertriglyceridemia } \\
\text { OR (CI 95\%) }\end{array}$ & $\begin{array}{c}\text { Hypercholesterolemia OR } \\
(\text { CI 95\%) }\end{array}$ & $\begin{array}{c}\text { High CT/CHDL } \\
\text { OR (CI 95\%) }\end{array}$ & $\begin{array}{c}\text { High LDL-c/HDL-c } \\
\text { OR (CI 95\%) }\end{array}$ \\
\hline BMI $\left(\mathrm{kg} / \mathrm{m}^{2}\right)$ & $1.07(1.04-1.09)^{*}$ & $1.03(1.01-1.06)^{*}$ & $1.03(1.01-1.05)^{\star}$ & $1.02(1.01-1.04)^{\star}$ \\
Body fat (\%) & $1.04(1.02-1.06)^{*}$ & $1.02(1.00-1.03)^{\varsigma}$ & $1.02(1.00-1.03)^{*}$ & $1.02(1.01-1.03)^{\star}$ \\
WC $(\mathrm{cm})$ & $1.03(1.019-1.04)^{*}$ & $1.019(1.10-1.03)^{*}$ & $1.012(1.01-1.02)^{*}$ & $1.01(1.01-1.02)^{\star}$ \\
\hline
\end{tabular}

OR: odd ratio; CI: Confidence Interval; ${ }^{*} \mathrm{p}<0.01 ; \$ \mathrm{p}<0.1$, BMI: Body mass index, WC: Waist circumference. 


\section{Discussion}

Cardiovascular diseases and metabolic disorders including obesity, diabetes and their relationship with dyslipidemia have been poorly documented in Cameroon. Data published have been obtained from patients in hospital centers only [27] [28]. The present study reports on larger sample of apparently healthy participants, recruited randomly in Yaounde. The study population was made of relatively young individuals (Table 1 ) with men aged $36.08 \pm 0.59$ years, and women aged $36.13 \pm 0.37$ years. Up to seventy-two $(72.6 \%)$ individuals ( $31 \%$ overweight and $41.6 \%$ obese) displayed pattern of malnutrition by excess vs $27.4 \%$ of normal-weight. This study revealed that levels of triglycerides, Total cholesterol and LDL-cholesterol were higher in obese than overweight and normal-weight individuals (Table 2). Increase of lipid markers with increasing BMI was in accordance with findings of Niroumand et al. [29] in Iranian population. From normal-weight to obese, lipid values obtained were relatively low when compared to other populations [25] [30]. This result is in accordance with Taga findings (2004) [31] on Cameroonian and supported by Glew et al. [32] who reported lower lipid profile amongst Africans compared to Caucasians [33].

Change in anthropometry due to fat accumulation, is accompanied with disturbances of lipid metabolism called dyslipidemia [17]. Normal-individuals have normal proportions of lean and fat tissues, this justifies their exclusion in the assessment of dyslipidemia. Dyslipidemia in the study was characterized by relatively low prevalence of hypercholesterolemia (19.3\%), hypertriglyceridemia (11.64\%) and mixed hyperlipidemia (3.40\%) contrasting with very high prevalence of low HDL-c $(75.4 \%, \mathrm{p}=0.01)$ in both men and women (Table 3). Prevalence of hypertriglyceridemia was low compared to $32.5 \%$ found in Mexican American populations by Aguilar-salinas et al. [34]. Hypercholesterolemia was also lower than the $44 \%$ reported by Mac Lean et al., [35] in Canada. Another finding from US National Health Nutrition survey 2003-2006 population reported high prevalence of high LDL-c (27\%), Low HDL-C (23\%) and high triglyceridemia and mixed dyslipidemia 21\% [21] [36]. Disparities of genetic (ethnic), environmental and lifestyle can explain differences in prevalence. Predominance of low HDL-c was found high in the population at all age (Figure 3). This result confirms the study of Moor et al. [28] carried out on 264 patients in hospital based survey in Yaounde. Hypertriglyceridemia was observed in Men aged 30 - 39 years; hypercholesterolemia in those aged group 40 - 49 years. Amongst women of above 50 years, hypercholesterolemia was prevalent probably due to oestrogen disturbances and to post-menopausal status [37] [38] [39].

Visceral obesity has been associated to sick fat or adiposopathy develops due to ectopic fat accumulation when the adipose tissue cannot longer expand [40]. Abdominal fat has been associated to hypercholesterolemia, hypertriglyceridemia, lower HDL-C levels (Figure 2) and increased risk of cardiovascular diseases and complications [41] [42]. However, in the present study, low HDL-c was also predominant in the population, independently of fat location (Figure 3), even 
though regression analysis established waist circumference as the main variable in all dyslipidemia (Table 4) as previously demonstrated [43] [44]. The adnormally low level of HDL-cholesterol alters the entire lipid metabolism HDL-c is involved in the transfer of the excess cholesterol, which is further catabolized and excreted in the bile [17] [45] reducing its level. In addition, low level of HDL-cholesterol may compromise oxidative status and the immune system of an individual, given its proved anti-oxidative capacity, antithrombotic and anti-inflammatory properties [46] [47]. Low HDL-c has also been shown to strongly correlated atherogenic or CVD risks [17] as an independent predictor [48] [49] and probably justifies the high prevalence of atherogenic risk observed in this study. The prevalence high of low HDL-c amongst overweight and obese of this population is consequently responsible of the high prevalence of atherogenic risk (40.3\%), in both men and women, at all age (Figure 3) and independently of the fat location (Figure 2); atherognic indexes LDL-c/HDL-c, TC/HDL-c, Log (TG/HDL-c) being mathematical relationship of lipid markers are strongly associated to increase risk of cardiovascular diseases [29] [50] such as carotid intima-media thicknesses and coronary artery disease [51] [52].

It is important to notice that this study is conducted on participants with no diabetes and no hypertension, all things that make them apparently healthy. However, such individuals characterized by predominance of Low HDL-c, are susceptible of developing a frank metabolic syndrome in the future (over 10 years) as proved by many researchers [53] [54] [55]. Therefore, strategies for prevention and surveillance should be encouraged by Cameroonian government, in order to extend life expectancy and reduce the incidence of CVD. In addition to lifestyle changes including diet, exercise, weight loss, smoking cessation to improve HDL-c levels [18] [56], implementation of therapeutic measures with statins or in combination with niacin should be accompanied by a supplementation of nutrition/diet with fruits, plants, herbs, spices; all rich antioxidant sources [17] [57].

\section{Limitations of the Study}

Enrollment of participants by public announcement was likely to develop a selection of adherents who do not reflect the general universe of the Yaounde adult population. Also, lack of reports on physical activities and eating patterns of participants limited discussion of results presented.

\section{Conclusion}

Low HDL-cholesterolemia (75.4\%) was found to be the most common feature of metabolic syndrome present in both genders, at all age amongst Cameroonian adults with feature of malnutrition by excess living in Yaoundé. Low HDL-cholesterolemia also impacts on high cardiovascular risk (40.3\%). Therefore, promotion of healthy lifestyle, including good eating habits shall be encouraged by authorities to increase HDL-c level and reduce mortality from car- 
diovascular disease complications.

\section{Acknowledgements}

This work was partially supported by the Cameroon Ministry of Higher Education in the form of research modernization allowance granted to some investigators.

\section{Consent for Publication}

Not applicable.

\section{Availability of Data and Material}

Data and material are available upon request.

\section{Funding}

Not applicable.

\section{Authors' Contributions}

HCMY and BGKA conceived, designed the study and drafted the manuscript; BGKA, DK and FRN coordinated data collection and performed statistical analyses; HCMY, MWN, BRTT and JTN collected field data and conducted laboratory analyses; JLN and JO supervised the work, drafted and approved the final version of the manuscript.

\section{Conflicts of Interest}

The authors declare no conflicts of interest regarding the publication of this paper.

\section{References}

[1] Cappucio, F.P. and Michelle, A.M. (2016) Cardiovascular Disease and Hypertension in Sub-Saharan Africa: Burden, Risk and Interventions. Internal and Emergency Medicine, 11, 299-305. https://doi.org/10.1007/s11739-016-1423-9

[2] Keates, A.K., Ana, O.M., Mpiko, N., Karen, S. and Simon, S. (2017) Cardiovascular Disease in African: Epidemiological Profile and Challenges. Nature Reviews Cardiology, 14, 273-293. https://doi.org/10.1038/nrcardio.2017.19

[3] Osei-Yeboah, J., Owiredu, B.A., Norgbe, G.K., Lokpo, S.Y., Gyamfi, J., Allotey, E.A. and Attah, F.A. (2017) The Prevalence of Metabolic Syndrome and Its Components among People with Type 2 Diabetes in the Ho Municipality, Ghana: A Cross-Sectional Study. International Journal of Chronic Diseases, 2017, Article ID: 8765804. https://doi.org/10.1155/2017/8765804

[4] Kengne, A.P., Echouffo-Tcheugui, J., Sobgnwi, E. and Mbanya, J.C. (2013) New Insights on Diabetes Mellitus and Obesity in Africa. Part 1: Prevalence, Pathogenesis and Comorbidities. Heart, 99, 979-983. https://doi.org/10.1136/heartjnl-2012-303316

[5] Sabir, A.A., Jimoh, A., Iwuala, S.O., Isezuo, S.A., Bilbis, L.S., Aminu, K.U., Abuba- 
kar, S.A. and Saidu, Y. (2016) Metabolic Syndrome in Urban City of North-Western Nigeria: Prevalence and Determinants. The Pan African Medical Journal, 23, 19. https://doi.org/10.11604/pamj.2016.23.19.5806

[6] Ntentie, F.R., Ngondi, J.L., Azantsa, K.B.G., Santy, E.V., Dimodi, H.T., Mbong, A.M.-A., et al. (2014) Urbanization and Metabolic Syndrome in Cameroon: Alertness on Less Urbanized Areas. Endocrinology and Metabolic Syndrome, 3, 2.

[7] Azantsa, K.G.B., Ntentié, F.R., Mbong, M.A., Kengne, N.A.P., Kuaté, D., Dakam, W., Ngondi, J.L. and Oben, J. (2013) Body Mass Index, Blood Pressure and Hypertension Subtypes among Untreated Hypertensive Cameroonians. British Journal of Medicine and Medical Research, 3, 2119-2131.

https://doi.org/10.9734/BJMMR/2013/4685

[8] Tchoubi, S., Sobngwi-Tambekou, J., Noubia, N.J.J., Asangbeh, S.L., Nkoum, B.A. and Sobngwi, E. (2015) Prevalence and Risk Factors of Overweight and Obesity among Children Aged 6-59 Months in Cameroon: A Multistage, Stratified Cluster Sampling Nationwide Survey. PLoS ONE, 10, e0143215. https://doi.org/10.1371/journal.pone.0143215

[9] Wamba, P.C., Oben, E.J. and Cianflone, K. (2013) Prevalence of Overweight, Obesity, and Thinness in Cameroon Urban Children and Adolescents. Journal of Obesity, 2013, Article ID: 737592. https://doi.org/10.1155/2013/737592

[10] Yangoua, M.C.H., Azantsa K.G.B., Ntentié, F.R., Ngondi, J.L. and Oben, J. (2010) Prevalence of Insulin Resistance in Obese Cameroonian Women. Journal of Diabetes and Endocrinology, 1, 19-26.

[11] WHO (1998) Obesity Preventing and Managing the Global Epidemic. Report of a WHO Consultation on Obesity. World Health Organization, Geneva.

[12] WHO (2000) Preventing and Managing the Global Epidemic. Report of a WHO Consultation. WHO Technical Report Series, No. 894, 1-253.

[13] Nigro, E., Scudiero, O., Monaco, M.L., Palmieri, A., Mazzarella, G., Costagliola, C., et al. (2014) New Insight into Adiponectin Role in Obesity and Obesity-Related Diseases. BioMed Research International, 2014, Article ID: 658913. https://doi.org/10.1155/2014/658913

[14] Bray, G.A. and Bellanger, T. (2006) Epidemiology, Trends, and Morbidities of Obesity and the Metabolic Syndrome. Endocrine, 29, 109-117. https://doi.org/10.1385/ENDO:29:1:109

[15] De Lorenzo, A., Soldati, L., Sarlo, F., Calvani, M., Di Lorenzo, N. and Di Renzo, L. (2016) New Obesity Classification Criteria as a Tool for Bariatric Surgery Indication. World Journal of Gastroenterology, 2, 681-703. https://doi.org/10.3748/wjg.v22.i2.681

[16] Shuldiner, A.R. (2008) Obesity Genes and Gene-Environment-Behavior Interactions: Recommendations for a Way Forward. Obesity (Silver Spring), 16, 79-81. https://doi.org/10.1038/oby.2008.523

[17] Ge, P., Dong, C.X., Ren, X.L., Weiderpass, E., Zhang, C.J., et al. (2015) The High Prevalence of Low HDL-Cholesterol Levels and Dyslipidemia in Rural Populations in Northwestern China. PLoS ONE, 10, e0144104. https://doi.org/10.1371/journal.pone.0144104

[18] Shao, H., Chen, L.Q. and Xu, J. (2011) Treatment of Dyslipidemia in the Elderly. Journal of Geriatric Cardiology, 8, 55-64. https://doi.org/10.3724/SP.J.1263.2011.00055

[19] Zhao, S., Wang, Y.J., Mu, Y.M., Yu, B.L., Ye, P., et al. (2014) Prevalence of Dyslipi- 
daemia in Patients Treated with Lipid-Lowering Agents in China. International Study Atherosclerosis, 235, 463-469.

https://doi.org/10.1016/j.atherosclerosis.2014.05.916

[20] Heymsfield, S., Peterson, C.M., Thomas, D.M., Heo, M. and Schuna, J.M. (2016) Why Are There Race/Ethnic Differences in Adult Body Mass Index-Adiposity Relationships? A Quantitative Critical Review. Obesity Reviews, 17, 262-275. https://doi.org/10.1111/obr.12358

[21] Pu, J., Romanelli, R., Zhao, B., Azar, K.M.J., Hastings, K.G., Nimbal, V., Fortmann, S.P. and Palaniappan, L.P. (2015) Dyslipidemia in Special Ethnic Populations. Cardiology Clinics, 33, 325-333. https://doi.org/10.1016/j.ccl.2015.01.005

[22] Phillips, C.M. (2013) Metabolically Healthy Obesity: Definitions, Determinants and Clinical Implications. Reviews in Endocrine and Metabolic Disorders, 14, 219-227. https://doi.org/10.1007/s11154-013-9252-x

[23] Monach, P.A. (2012) Repeating Tests: Different Roles in Research Studies and Clinical Medicine. Biomarkers in Medicine, 6, 691-703. https://doi.org/10.2217/bmm.12.57

[24] Friedwald, W.T., Levy, R.I. and Frederickson, D.S. (1972) Estimation of the Concentration of Low Density Lipoprotein Cholesterol in Plasma, without Use of the Preparative Ultracentrifuge. Clinical Chemistry, 18, 499-502.

[25] Expert Panel on Detection, Evaluation, and Treatment of High Blood Cholesterol in Adults (2001) Executive Summary of the Third Report of the National Cholesterol Education Program (NCEP) Expert Panel on Detection, Evaluation and Treatment of High Blood Cholesterol in Adults (Adult Treatment Panel III). JAMA, 285, 2486-2487. https://doi.org/10.1001/jama.285.19.2486

[26] Onat, A., Can, G., Kaya, H. and Hergenç, G. (2010) “Atherogenic Index of Plasma” (Log10 Triglyceride/High-Density Lipoprotein-Cholesterol) Predicts High Blood Pressure, Diabetes, and Vascular Events. Journal of Clinical Lipidology, 4, 89-98. https://doi.org/10.1016/j.jacl.2010.02.005

[27] Dobiásová, M., Frohlich, J., Sedová, M., Cheung, M.C. and Brown, B.G. (2011) Cholesterol Esterification and Atherogenic Index of Plasma Correlate with Lipoprotein Size and Findings on Coronary Angiography. The Journal of Lipid Research, 52, 566-561. https://doi.org/10.1194/jlr.P011668

[28] Moor, V.J.A., Amougou, S.N., Ombotto, S., Ntone, F., Wouamba, E. and Nonga, B.N. (2017) Dyslipidemia in Patients with a Cardiovascular Risk and Disease at the University Teaching Hospital of Yaoundé, Cameroon. International Journal of Vascular Medicine, 2017, Article ID: 6061306. https://doi.org/10.1155/2017/6061306

[29] Niroumand, S., Mohammad, K., Majid, K.-R., Maryam, A., Mohammadreza, J., Gholamhasan, K., et al. (2015) Atherogenic Index of Plasma (AIP, A Marker of Cardiovascular Disease. Medical Journal of the Islamic Republic of Iran, 29, 240.

[30] WHO (1995) Physical Status: The Use and Interpretation of Anthropometry. World Health Organization, Geneva.

[31] Taga, I., Kouemeni, L. and Ngogang, Y.J. (2004) Valeurs de référence des lipides sériques chez de jeunes hommes camerounais. Note Scientifique. Annales de Biologie Clinique, 41, 33-38.

[32] Glew, R.H., William, M., Conn, C.A., Cadena, S.M., Crossey, M., et al. (2001) Cardiovascular Disease Risk Factors and Diet of Fulani Pastoralists of Northern Nigeria. The American Journal of Clinical Nutrition, 74, 730-736. https://doi.org/10.1093/ajcn/74.6.730 
[33] Adams-Cambel, L.L., Nwankwo, M.U., Omene, J.A., Ukoli, F.A., Young, M.P., Haile, G.T. and Kuller, L.H. (1988) Assessment of Cardiovascular Risk Factors in Nigerian Students. Arteriosclerosis, 8, 793-796. https://doi.org/10.1161/01.ATV.8.6.793

[34] Aguilar-Salinas, C.A., Olaiz, G., Valles, V., Ríos, T.J.M., Gómez, P.F.J., et al. (2001) High Prevalence of Low HDL Cholesterol Concentrations and Mixed Hyperlipidemia in a Mexican Nationwide Survey. The Journal of Lipid Research, 42, 1298-1307.

[35] MacLean, D., Petrasovits, A., Connelly, P., Joffres, M., O’Connor, B. and Little, J. (1999) Plasma Lipids and Lipoprotein Reference Values, and the Prevalence of Dyslipoproteinemia in Canadian Adults. Canadian Heart Health Surveys Research Group. Canadian Journal of Cardiology, 15, 434-444.

[36] Toth, P.P., Potter, D. and Ming, E.E. (2012) Prevalence of Lipid Abnormalities in the United States: The National Health and Nutrition Examination Survey 2003-2006. Journal of Clinical Lipidology, 6, 325-330. https://doi.org/10.1016/j.jacl.2012.05.002

[37] Nwagha, U.I., Ikekpeazu, E.J., Ejezie, F.E., Neboh, E.E. and Maduka, I.C. (2010) Atherogenic Index of Plasma as Useful Predictor of Cardiovascular Risk among Postmenopausal Women in Enugu, Nigeria. African Health Sciences, 10, 248-252.

[38] Souza, L.J., Souto, F.J., Souza, T.F., Reis, A.F.F., Neto, C.G., Bastos, D.A., Côrtes, A.V., Chalita, B.F.E. and Teixeira, C.L. (2003) Prevalence of Dyslipidemia and Risk Factors in Campos Dos Goytacazes, in the Brazilian State of Rio de Janeiro. Arquivos Brasileiros de Cardiologia, 81, 249-264. https://doi.org/10.1590/S0066-782X2003001100005

[39] Li, Z., Mcnamara, J.R., Fruchart, J.C., Luc, G., Bard, J.M., Ordovas, J.M., Wilson, P.W. and Schaefer, E.J. (1996) Effects of Gender and Menopausal Status on Plasma Lipoprotein Subspecies and Particle Sizes. The Journal of Lipid Research, 37, 1886-1896.

[40] Smith, U. (2015) Abdominal Obesity: A Marker of Ectopic Fat Accumulation. The Journal of Clinical Investigation, 125, 1790-1792. https://doi.org/10.1172/JCI81507

[41] WHO (2011) Global Status Report on Non-Communicable Diseases 2010. World Health Organization, Geneva.

[42] Azhar, W., Buczkowski, B., Smith, C. and Onambele-Pearson, G. (2018) Impact of Circulating Triglycerides Concentration on Atherosclerotic Disease Status in Middle-Aged Saudi Arabian Dwellers. Nutrients, 10, 1642.

[43] Fezeu, L., Balkau, B., Kengne, A.-P., Sobngwi, E. and Mbanya, J.C. (2006) Metabolic Syndrome in a Sub-Saharan African Setting: Central Obesity May Be the Key Determinant. Atherosclerosis, 193, 70-76.

https://doi.org/10.1016/j.atherosclerosis.2006.08.037

[44] Chehrei, A., Sadrnia, S., Keshteli, H.A., Daneshmand, A.M. and Rezaei, J. (2007) Correlation of Dyslipidemia with Waist to Height Ratio, Waist Circumference, and Body Mass Index in Iranian Adults. Asia Pacific Journal of Clinical Nutrition, 16, 248-253.

[45] Lin, Y., Mousa, S.S., Elshourbagy, N. and Mousa, S.A. (2010) Current Status and Future Directions in Lipid Management: Emphasizing Low-Density Lipoproteins, High-Density Lipoproteins, and Triglycerides as Targets for Therapy. Vascular Health and Risk Management, 6, 73-85. https://doi.org/10.2147/VHRM.S8725

[46] Alwaili, K., Awan, Z., Alshahrani, A. and Genest, J. (2010) High-Density Lipoproteins and Cardiovascular Disease: 2010 Update. Expert Review of Cardiovascular Therapy, 8, 413-423. https://doi.org/10.1586/erc.10.4 
[47] Degoma, E.M., Leeper, N.J. and Heidenreich, P.A. (2008) Clinical Significance of High-Density Lipoprotein Cholesterol in Patients with Low-Density Lipoprotein Cholesterol. Journal of the American College of Cardiology, 51, 49-55. https://doi.org/10.1016/j.jacc.2007.07.086

[48] Millan, J., Xavier, P., Muñoz, A., Zuñiga, M., Rubies-Prat, J., Felipe, P., et al. (2009) Lipoprotein Ratios: Physiological Significance and Clinical Usefulness in Cardiovascular Prevention. Vascular Health and Risk Management, 5, 757-765. https://doi.org/10.2147/VHRM.S6269

[49] Lewis, B., Assmann, G., Tikkanen, M., Mancini, M. and Pometta, D. (1992) Prevention of Coronary Heart Disease: Scientific Background and New Clinical Guidelines. Recommendations of the European Atherosclerosis Society, Prepared by the International Task Force for Prevention of Coronary Heart Disease. Nutrition, Metabolism and Cardiovascular Diseases, 2, 113-156.

[50] Mudhaffar, S.K. (2013) Atherogenic Index of Plasma (AIP) as a Parameter in Predicting Cardiovascular Risk in Males Compared to the Conventional Dyslipidemic Indices (Cholesterol Ratios). Karbala Journal of Medicine, 6, 1506-1513.

[51] Zhu, X., Yu, L., Hui, Z., Qinhua, M., Xiaohua, Z., Ting, L., et al. (2018) Atherogenic Index of Plasma Is a Novel and Better Biomarker Associated with Obesity: A Population-Based Cross-Sectional Study in China. Lipids in Health and Disease, 17, 37. https://doi.org/10.1186/s12944-018-0686-8

[52] Cai, G., Shi, G., Xue, S. and Lu, W. (2017) The Atherogenic Index of Plasma Is a Strong and Independent Predictor for Coronary Artery Disease in the Chinese Han Population. Medicine (Baltimore), 96, e8058. https://doi.org/10.1097/MD.0000000000008058

[53] Soriguer, F., Gutierrez-Repiso, C., Rubio-Martin, E., García-Fuentes, E., Almaraz, M.C., Colomo, N., et al. (2013) Metabolically Healthy But Obese, a Matter of Time? Findings from the Prospective Pizarra Study. The Journal of Clinical Endocrinology \& Metabolism, 98, 2318-2325. https://doi.org/10.1210/jc.2012-4253

[54] Appleton, S.L., Seaborn, C.J., Visvanathan, R., Hill, C.L., Gill, T.K. and Taylor, A.W. (2013) Diabetes and Cardiovascular Disease Outcomes in the Metabolically Healthy Obese Phenotype: A Cohort Study. Diabetes Care, 36, 2388-2394. https://doi.org/10.2337/dc12-1971

[55] Hwang, Y.C., Hayashi, T., Fujimoto, W.Y., Kahn, S.E., Leonetti, D.L., Mcneely, M.J. and Boyko, E.J. (2015) Visceral Abdominal Fat Accumulation Predicts the Conversion of Metabolically Healthy Obese Subjects to an Unhealthy Phenotype. International Journal of Obesity, 39, 1365-1370. https://doi.org/10.1038/ijo.2015.75

[56] Rosenson, R.S. (2005) Low HDL-C: A Secondary Target of Dyslipidemia Therapy. The American Journal of Medicine, 118, 1067-1077. https://doi.org/10.1016/j.amjmed.2004.12.021

[57] Rutherford, J.N., Mcdade, T.W., Feranil, A.B., Adair, L.S. and Kuzawa, C.W. (2010) High Prevalence of Low HDL-c in the Philippines Compared to the US: Population Differences in Associations with Diet and BMI. Asia Pacific Journal of Clinical $\mathrm{Nu}$ trition, 19, 57-67. 